\title{
LA OCULTACión MONETAL DE LA D'EULA, CREVILLENTE (ALICANTE) Y SU SIGNIFICACIÓN PARA EL ESTUDIO DE LAS INVASIONES DEL SIGLO III
}

\author{
ALFREDO GONZÁLEZ PRATS \\ JUAN MANUEL ABASCAL PALAZÓN \\ Universidad de Alicante
}

\begin{abstract}
La ocultación monetal de La D'Eula (Crevillente, Alicante), contiene un conjunto de monedas datables entre los años 222 y 260 , asociadas a algunos ejemplares más antiguos; las circunstancias del hallazgo y el análisis del mismo sugieren que el conjunto sea otro testimonio de las invasiones germánicas del siglo III d. C.
\end{abstract}

The monetary occultation of La Eula (Crevillente, Alicante) contains a coin group, dated between the years 222 and 260, associated to some older exemples; the circumstances of the discovery and its analysis suggest that the ensemble is testimony of the Germanic invasion of the III century A. D.

El conocimiento y estudio del conjunto monetal que aquí se presenta, ha sido propiciado por la inestimable colaboración de don Alfonso Candela y don Manuel Pérez, vecinos de Crevillente, quienes de forma casual localizaron las piezas cuando se reparaba el margen de contención de uno de los bancales situados en la parte baja del municipio.

El hallazgo se produjo en el paraje denominado La D'Eula, situado aproximadamente a $2 \mathrm{Km}$. al SE del pueblo, lugar en donde se vienen registrando diversos hallazgos arqueológicos de época ibérica y, sobre todo, romana. El lugar debió ser un extenso núcleo de población, sin que hasta el presente se hayan efectuado trabajos científicos que posibiliten su correcta valoración.

Las piezas aparecieron, según indicación de sus descubridores, en compañía de un vaso de cerámica común (búcaro) de pasta ocre-anaranjada, fractu- rado e incompleto, en el que presumiblemente habrían estado contenidas las monedas.

El lote está constituído por siete antoninianos y cincuenta y cinco sestercios, datables entre los reinados de Nerón y Galieno, aunque con grandes lagunas en diferentes períodos. Hemos de advertir que trece sestercios no han podido ser clasificados debido a su mal estado de conservación, por lo que no se han tenido en cuenta en las valoraciones estadísticas. En consecuencia, el lote utilizable queda formado por cuarenta y nueve ejemplares.

Dentro del total destaca el conjunto datable entre los años 222 y 259 , con treinta y cinco ejemplares, frente a una agrupación menos significativa de catorce piezas entre los años 54 a 180. La distribución temporal recogida en la fig. 3 muestra cómo entre las monedas anteriores al año 222 tan sólo están representados algunos reinados de modo arbi- 


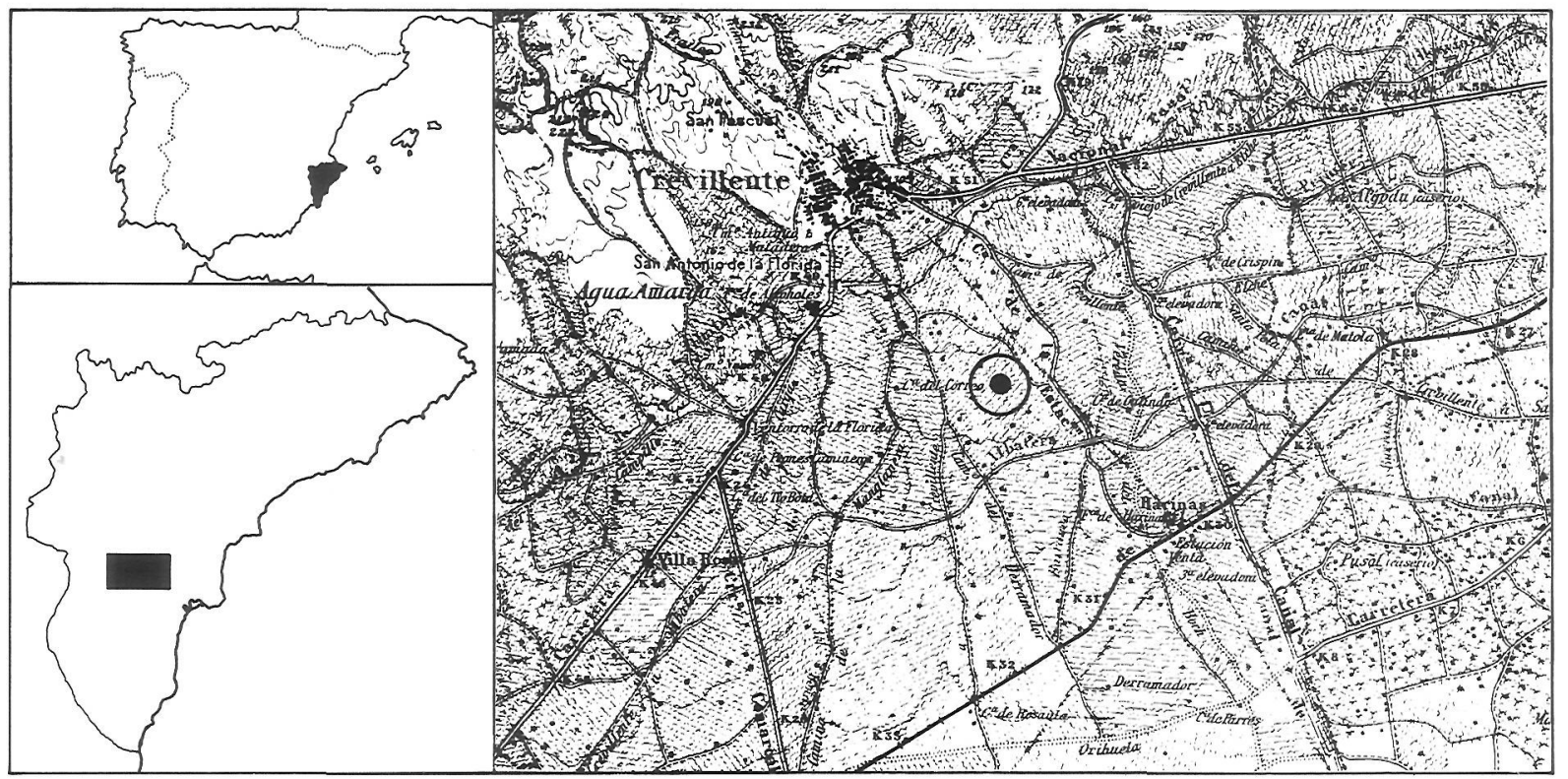

Fig. 1.-Plano de situación del lugar del hallazgo.

trario, a excepción de los de Antonino Pío y Marco Aurelio-Lucio Vero, con un total de doce piezas sobre las catorce existentes. Este hecho podría indicar que en el momento del hallazgo quedó afectado el nivel de ocupación del yacimiento correspondiente a dicha época. Por el contrario, el numerario del segundo período (222-259) presenta una fuerte homogeneidad y una clara sucesión de los diferen-

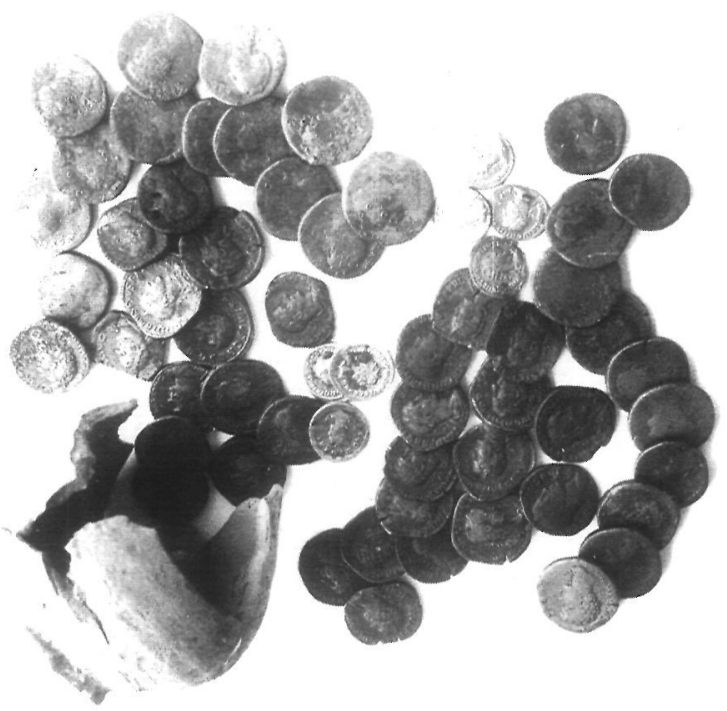

Fig. 2.-El conjunto monetal junto con el recipiente que, presumiblemente, contenía una parte del mismo. tes reinados con excepciones poco relevantes. Este segundo lote es, en su mayoría, de moneda circulante, por lo que el carácter de ocultación y las conclusiones históricas que de ello se desprendan deberán referirse exclusivamente a este grupo de piezas. Y ellas son las que deben asociarse a la vasija cerámica que habría servido para ocultarlas, como bien delatan las concreciones de óxidos en su interior. La ausencia de la parte superior del vaso podría obedecer a una posterior alteración debida a las modernas labores agrícolas, causa de la fractura de la pieza.

\section{CATÁlogo}

Las indicaciones numéricas de las piezas se sitúan en el siguiente orden: Peso en gramos, módulo en milímetros y posición de cuños siguiendo las señales horarias.

1.-NERÓN. Sestercio. Roma.

$A$. Emperador a derecha. Leyenda borrada.

$R$. Borrado.

19,6/32/--.

2.-DOMICIANO?. Sestercio. Roma.

$A$. Emperador a derecha. Leyenda borrada. $R$. Minerva. Con lanza y escudo. Resto borrado.

$22,9 / 31,3 / 4$. 


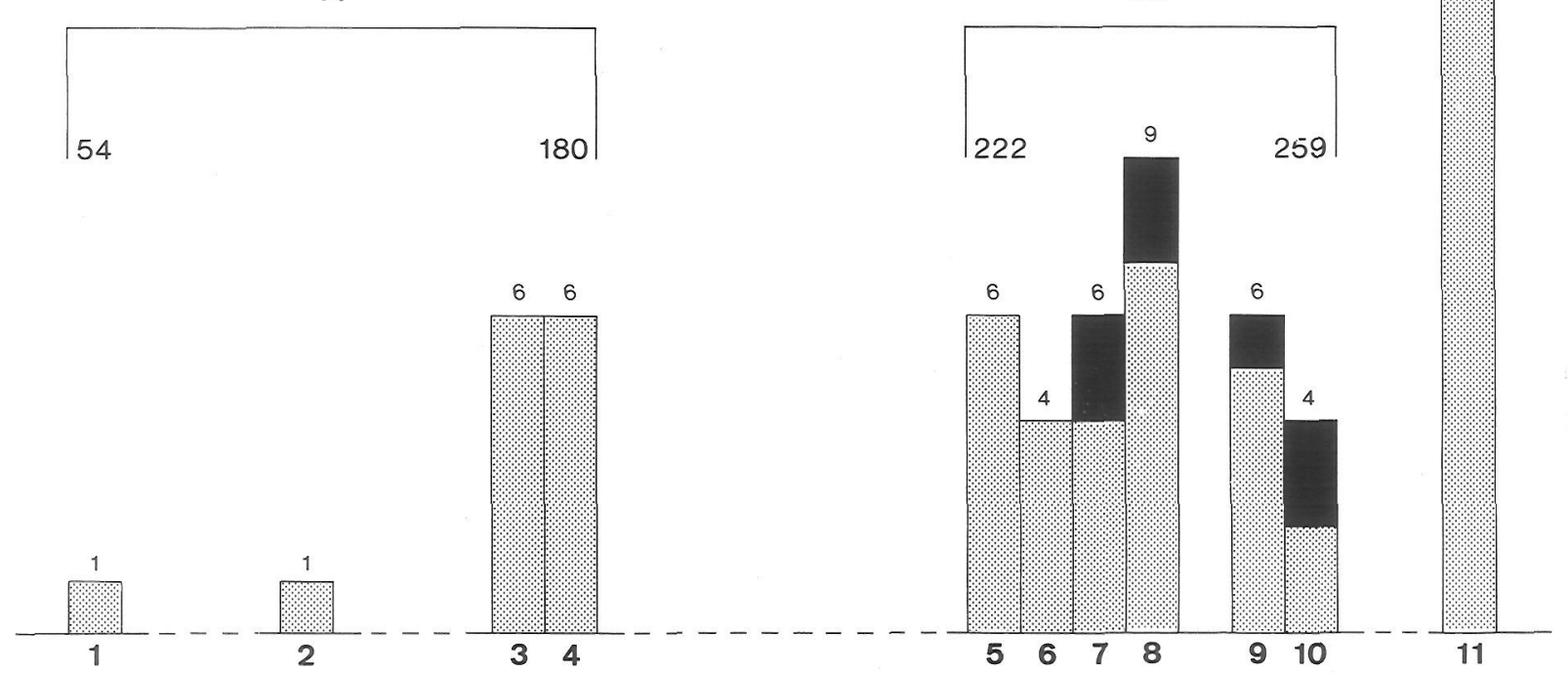

Fig. 3.-Gráfico cuantitativo del hallazgo repartido por reinados. La superficie tramada representa las piezas de bronce (sestercios), mientras que la zona negra alude a las de plata. Leyenda.-1: Nerón; 2: Domiciano; 3: Antonino Pío; 4: Marco Aurelio-Lucio VeroFaustina II; 5: Alejandro Severo-Iulia Mamaea; 6: Maximino I-Máximo; 7: Gordiano III; 8: Filipo I-Filipo II-Otacilia; 9: Treboniano Galo-Emiliano; 10: Valeriano-Galieno-Salonina; 11: Piezas no clasificadas a causa de su deficiente conseración.

3.-ANTONINO PÍO. Sestercio. Roma.

A. [--]ANTONINVS[--]?. Busto a derecha (resto borrado).

$R$. SC (resto borrado). Figura femenina con pátera en mano derecha sosteniendo el manto con la izquierda.

$20,7 / 29,4 / 1$.

4.-ANTONINO PÍO. Sestercio. 154-155. Roma. A. ANTONINVS AVG PIVS PP TR P XVIII. Busto a la derecha.

$R$. LIBERTAS COS IIII SC. Libertas estante de frente con cabeza a la derecha, sosteniendo pileus y con una lanza en el brazo izquierdo. 21,7/30,8/11.

MATTINGLY 1968, n. ${ }^{\circ} 1962$.

5.-ANTONIO PÍO. Sestercio. 156-157?. Roma. A. IMP CAES T AEL HADR ANTONINVS AVG PIVS PP. Busto a derecha. $R$. SC (resto leyenda borrada). Annona sentada sosteniendo espiga y cornucopia. $23,3 / 32,3 / 5$.

RIC 948 .
6.-ANTONINO PÍO. Sestercio. Roma.

$A$. Leyenda borrada. Emperador a derecha. $R$. SC (resto leyenda borrada). Concordia con pátera.

21,5/31,5/6.

7.-ANTONINO PÍO. Sestericio. Roma. A. [--]ANTONINVS[--] (resto leyenda borrada). Emperador a derecha.

$R$. SC (resto borrada). Libertas con pileus $y$ lanza.

$20,8 / 30,2 / 5$.

8.-ANTONINO PÍO. Sestercio. Roma.

A. ANTONINVS AVG PIVS (?). (Resto borrada). Emperador a derecha.

$R$. SC (resto borrada). Figura femenina sentada con cornucopia en la mano derecha. $20,4 / 31,4 / 12$.

9.-MARCO AURELIO. Sestercio. c.161. Roma. A. IMP CAES M AVREL ANTONINVS AVG PM. Emperador a derecha. $R$. CONCORD AVGVSTOR TR P XV SC. 
Exergo: COS III. Marco Aurelio y Lucio Vero en pie.

23,5/32,5/11.

MATTINGLY, 1968, n. $^{\circ} 847$.

10.-MARCO AURELIO. Sestercio. Roma.

A. Leyenda borrada. Emperador a derecha.

$R$. Leyenda borrada. Figura en pie.

23,3/32/11.

11.-MARCO AURELIO. Sestercio. Roma.

A. Leyenda borrada. Emperador a derecha.

$R$. SC (resto borrado). Figura femenina en pie.

$22,6 / 32 / 12$.

12.-FAUSTINA II. Sestercio. c.161. Roma.

A. FAVSTINA (resto leyenda borrada). Busto

de Faustina con el pelo recogido.

$R$. Leyenda borrada. Figura femenina en pie.

$21,4 / 31,7 / 11$.

13.-FAUSTINA II. Sestercio. c.161. Roma.

A. Semejante.

$R$. Leyenda borrada. Figura femenina en pie. $25,6 / 30,9 / 11$.

14.-LUCIO VERO. Sestercio. 161. Roma.

A. IMP CAES L AVREL VERVS AVG.

Busto drapeado a la derecha.

$R$. Leyenda borrada. (Frustra).

21,6/31/--.

MATTINGLY, 1968, p. 521.

15.-ALEJANDRO SEVERO. Sestercio. 225. Roma.

A. IMP CAES M AVR SEV ALEXANDER

AVG. Emperador laureado y con coraza, a derecha.

R. FIDES MILITUM SC. Fides en pie, sosteniendo un estandarte en cada mano.

$25,3 / 31 / 11$.

RIC, 552c.

16.-ALEJANDRO SEVERO. Sestercio. 231-235. Roma.

A. IMP ALEXANDER PIVS AVG. Emperador a derecha, laureado y togado.

R. MARS VLTOR SC. Marte avanzando con lanza y escudo.

$18 / 29,3 / 11$.

RIC, 635.

17.-ALEJANDRO SEVERO. Sestercio. 231-235. Roma.

A. IMP ALEXANDER PIVS AVG. Emperador laureado a derecha.
R. PROVIDENTIA AVG SC. Providentia con cabeza ladeada sosteniendo espigas sobre un modio en la mano derecha y una cornucopia en la izquierda.

$15,5 / 30,6 / 12$.

RIC, 642-643

18.-JULIA MAMAEA. Sestercio. Roma.

A. IVLIA MAMAEA A V GVSTA. Busto diademado a la derecha.

$R$. VESTA SC. Vesta velada sujetando paladium y cetro.

20,8/31,8/12.

RIC, 708.

19.-JULIA MAMAEA. Sestercio. Roma.

A. IVLIA MAMAEA AVGVSTA. Busto diademado a derecha.

R. FECUNDITAS AVGVSTAE SC. Fecunditas portando cornucopia y extendiendo la mano a un niño.

$22 / 31,3 / 6$

RIC, 668.

20.-JULIA MAMAEA. Sestercio. 231-235. Roma. A. IVLIA MAMAEA AVGVSTA. Busto diademado a derecha.

$R$. FELICITAS PVBLICA SC. Felicitas sentada sosteniendo caduceo y cormucopia.

$19,6 / 30,3 / 1$.

RIC, 679.

21.-MAXIMINO I. Sestercio. Marzo 235-enero 236. Roma.

A. IMP MAXIMINVS PIVS AVG. Emperador laureado a derecha.

$R$. VICTORIA AVG SC. Victoria avanzando sosteniendo una palma.

$19,3 / 31,6 / 1$.

RIC, 67.

22.-MAXIMINO I. Sestercio. Marzo 235-enero 236. Roma.

$A$. Semejante.

R. PROVIDENTIA AVG SC. Providentia sosteniendo cornucopia.

20,9/30,9/1.

RIC, 61 .

23.-MAXIMINO I. Sestercio. Marzo 235-enero 236. Roma.

A. Semejante.

R. PAX AVGVSTI SC. Pax estante, sujetando una lanza en la mano izquierda.

$18,7 / 30,5 / 12$.

RIC, 58. 


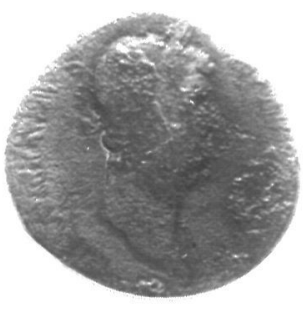

1

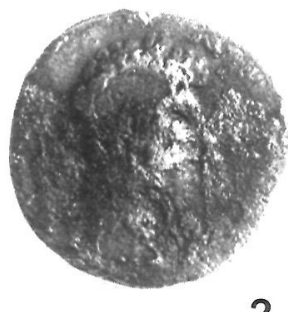

2

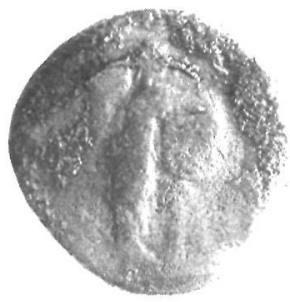

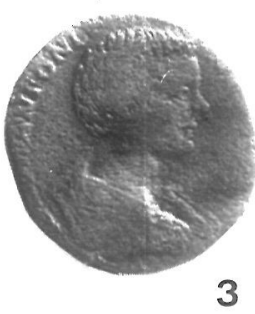

3

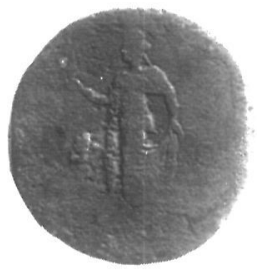

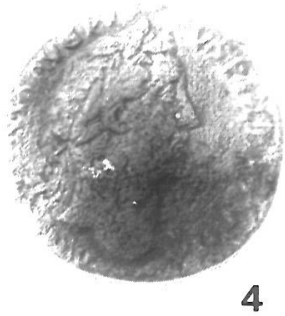

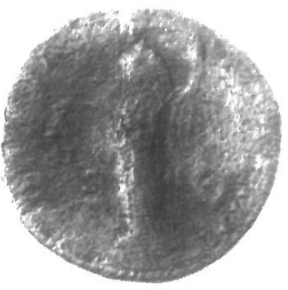

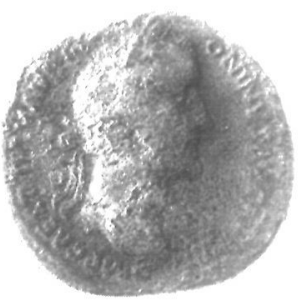

5
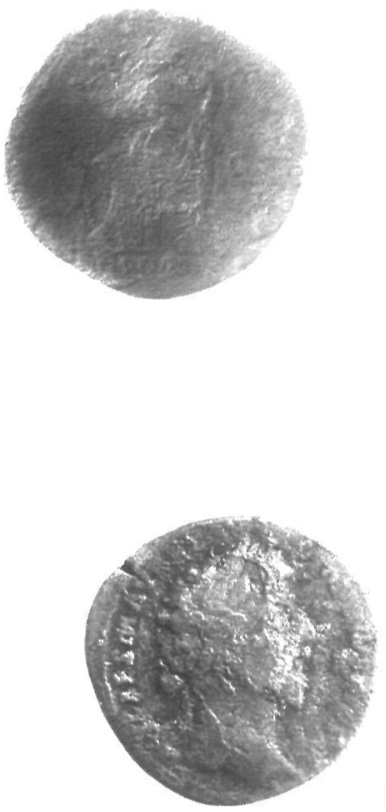

9
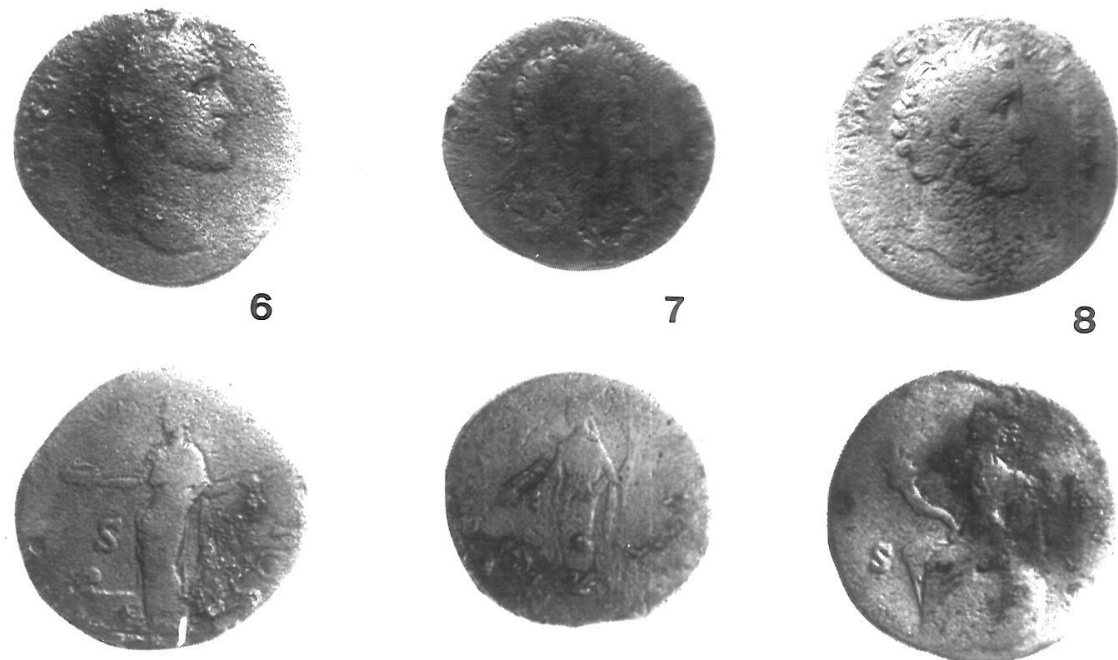

8
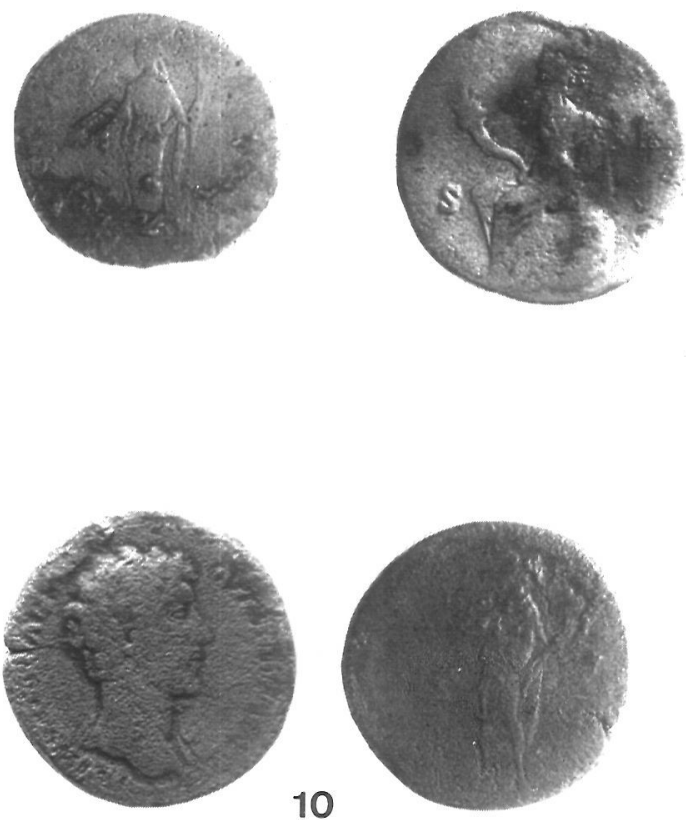

Lám. I.-Monedas de Nerón (n. $\left.{ }^{\circ} 1\right)$, Domiciano (n. ${ }^{\circ}$ 2), Antonino Pío (n. ${ }^{\circ}$ 3-8) y Marco Aurelio (n. ${ }^{\circ}$ 9-10). E.-1:1. 
24.-MÁXIMO. Sestercio. 236-238. Roma. A. MAXIMVS CAES GERM. Emperador a derecha.

$R$. PRINCIPI IVVENTVTIS SC. Máximo en pie junto a dos estandartes.

$25,2 / 31,4 / 1$.

RIC, 13.

25.-GORDIANO III. Antoniniano. 242. $4 .^{\mathrm{a}}$ emisión. Roma.

$A$. IMP GORDIANVS PIVS FEL AVG. Cabeza radiada a derecha.

$R$. PM TR P V COS II PP. Gordiano III en atuendo militar sosteniendo una lanza atravesada y un globo.

$4 / 23,2 / 6$.

RIC, 93.

26.-GORDIANO III. Antoniniano. 240-244.

Roma.

$A$. IMP GORDIANVS PIVS FEL AVG. Cabeza radiada a derecha.

$R$. VIRTVTI AVGVSTI. Hércules en pie apoyándose en una roca.

$2,76 / 24,1 / 8$.

RIC, 95.

27.-GORDIANO III. Sestercio. 241. 4. a emisión. Roma.

A. IMP GORDIANVS PIVS FEL AVG. Busto a derecha.

$R$. PM TR P IIII COS II PP. SC. Gordiano sentado sosteniendo una palma.

$25,9 / 32,4 / 1$

RIC, 302.

28.-GORDIANO III. Sestercio. 241-243. 4. ${ }^{\mathrm{a}}$ emisión. Roma.

A. IMP GORDIANVS PIVS FEL AVG. Busto a derecha.

$R$. AETERNITATI AVG. SC. Sol de frente y de pie con globo.

$17,7 / 30 / 11$.

RIC, 297a.

29.-GORDIANO III. Sestercio. 240-244. Roma. $A$. IMP GORDIANVS PIVS FEL AVG. Busto a derecha.

$R$. VICTORIA AETER SC. Victoria sujetando un cautivo y una palma.

$18,2 / 30,5 / 11$.

RIC, 337a.

30.-GORDIANO III. Sestercio. 240. Roma. $A$. IMP GORDIAN [us pius fel aug]. Empe- rador a derecha.

$R$. [pm tr p] III COS [II pp SC]. Emperador a derecha sosteniendo lanza y globo.

$15,5 / 28,1 / 1$.

RIC 305a.

31.-FILIPO I. Antoniniano. 244-247. Roma. $A$. IMP M IVL PHILIPPVS AVG. Cabeza radiada a derecha.

$R$. LIBERALITAS AVGG II. Liberalitas en pie sosteniendo ábaco y cornucopia.

$3,9 / 23,5 / 1$.

RIC, 38b.

32.-FILIPO I. Antoniniano. 244-247. Roma. $A$. IMP M IVL PHILIPPVS AVG. Cabeza radiada a derecha.

$R$. ANNONA AVGG. Annona en pie con cornucopia.

$3,9 / 22,5 / 5$.

RIC 28c.

33.-FILIPO I. Sestercio. 244-249. Roma.

$A$. IMP M [iul philippus] AVG. Busto a derecha.

R. ¿Fides militum? SC.

$17,9 / 27 / 11$.

34.-FILIPO I. Sestercio. 248. Roma.

A. IMP M IVL PHILIPPVS AVG. Busto a derecha.

$R$. SAECVLARES AVGG. Exergo: SC. Antílope avanzando hacia la izquerda.

$16,1 / 30,6 / 10$.

RIC, 161.

35.-FILIPO I. Sestercio. 247-249. Roma.

$A$. IMP M IVL PHILIPPVS AVG. Busto a derecha.

R. AEQVITAS AVGG. SC. Aequitas sosteniendo balanza y cornucopia.

$18,4 / 32,8 / 12$.

RIC, $166 a$.

36.-FILIPO I. Sestercio. 247-249. Roma.

Semejante.

$19,5 / 31,3 / 1$.

RIC, $166 \mathrm{a}$.

37.-FILIPO I. Sestercio. 247-249. Roma.

$A$. Semejante.

$R$. FORTVNA REDVX. Exergo: SC. Fortuna sentada sobre un carro, sosteniendo cornucopia.

15,8/30,1/11.

RIC, 174a (4 radios). 


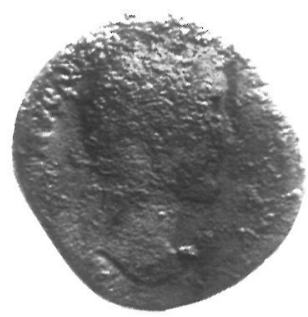

11

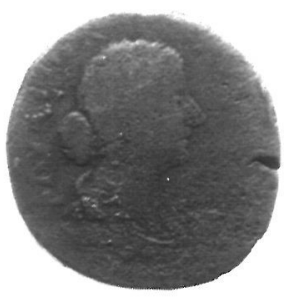

12

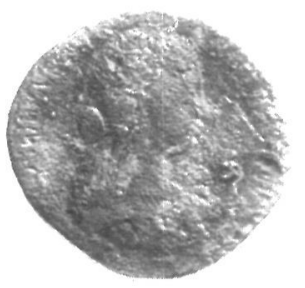

13
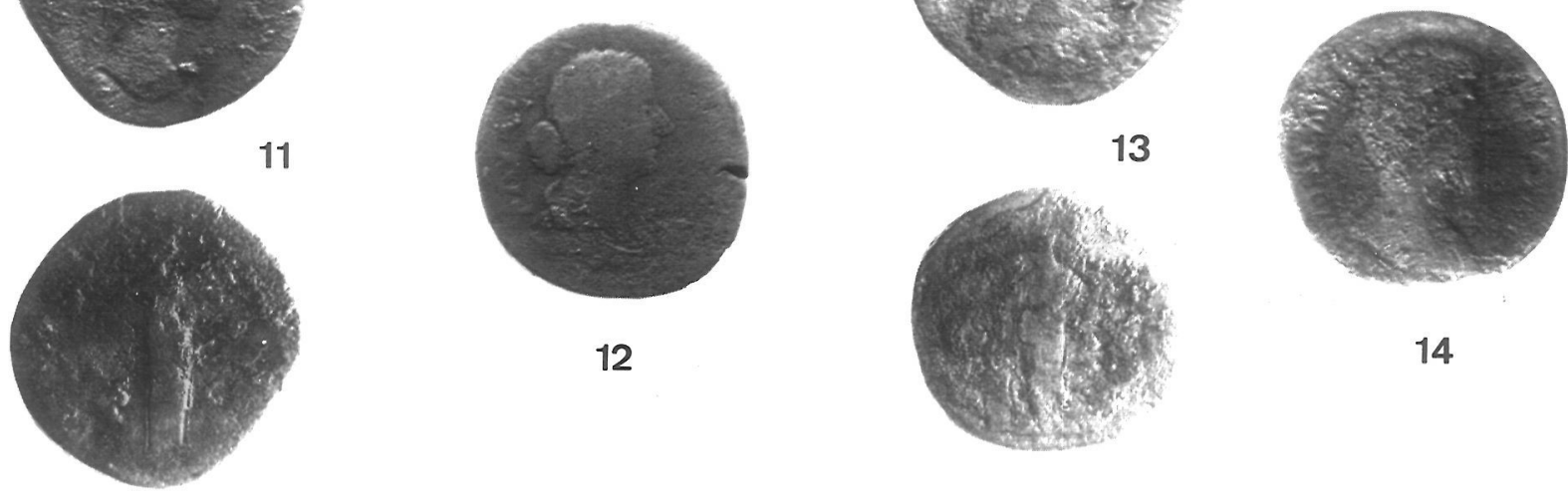

14

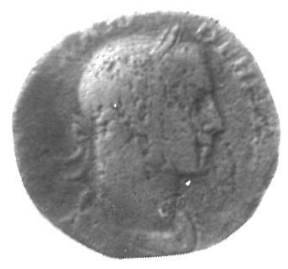

16
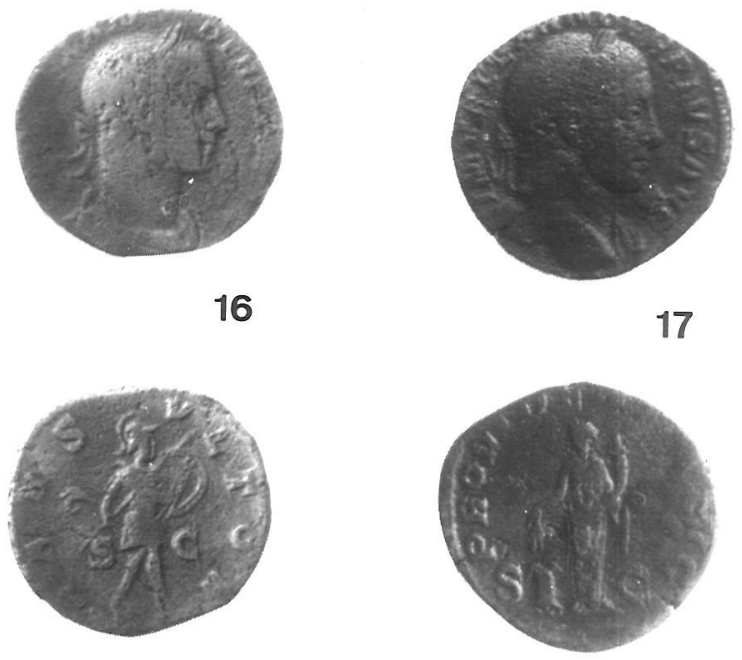

17
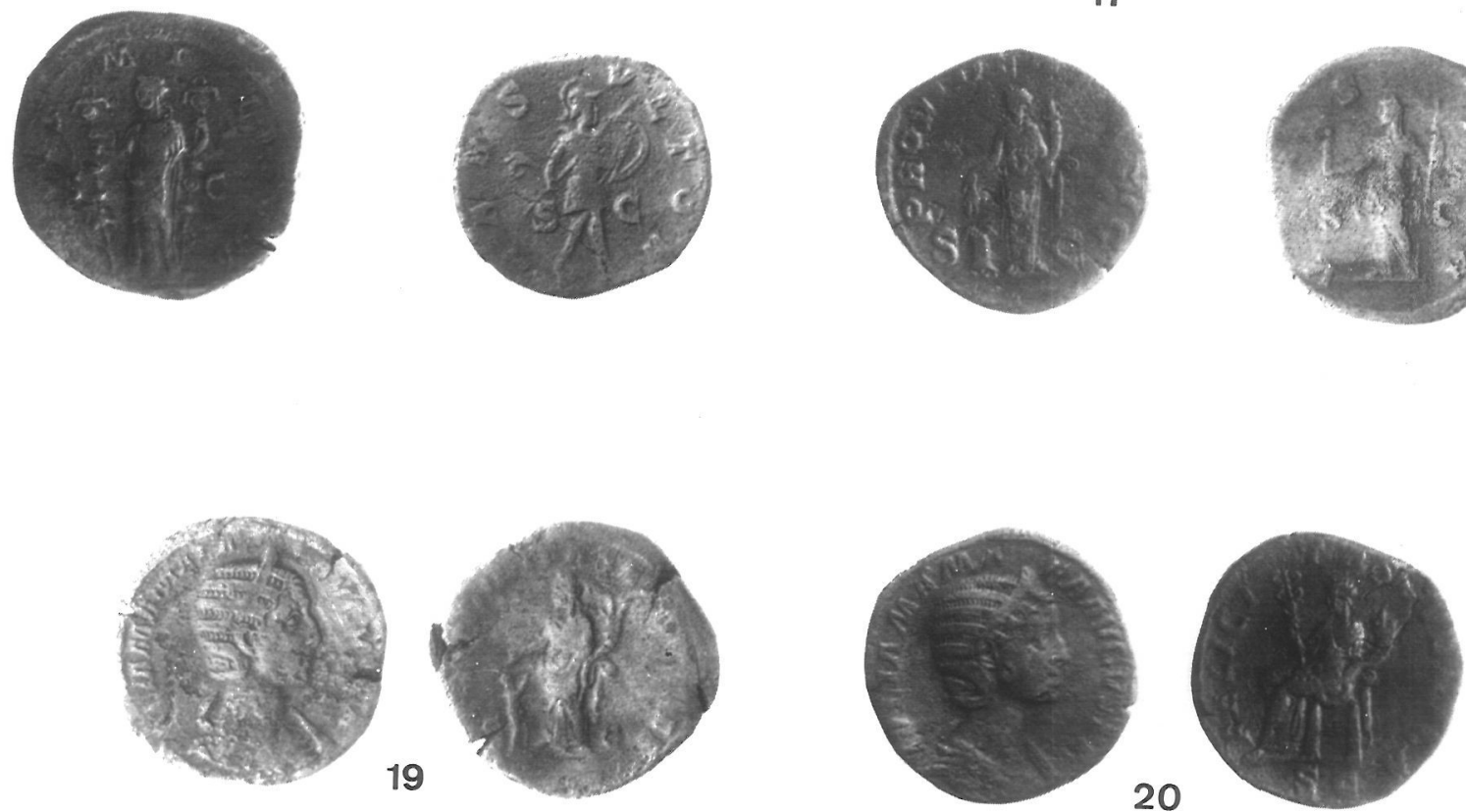

Lám. II.-Monedas de Marco Aurelio (n. $\left.{ }^{\circ} 11\right)$, Faustina II (n. $\left.{ }^{\circ} 12-13\right)$, Lucio Vero (n. $\left.{ }^{\circ} 14\right)$, Alejandro Severo (n. $\left.{ }^{\circ} 15-17\right)$ y Julia Mamaea (n. ${ }^{\circ}$ 18-20). E.-1:1. 
38.-OTACILIA SEVERA. Sestercio. 244-49. Roma.

A. MARCIA OTACIL SEVERA AVG. Busto diademado a la derecha.

R. CONCORDIA AVGG. Concordia sentada sosteniendo pátera y doble cornucopia.

Exergo: SC.

$14,4 / 30,1 / 12$.

RIC, 203.

39.-FILIPO II. Sestercio. 247-249. Roma.

A. IMP MIVL PHILIPPVS AVG. Busto a derecha.

R. VIRTVS AVGG SC. Marte en atuendo militar con estandarte y lanza.

$16,9 / 29,2 / 11$.

RIC, 263.

40.-TREBONIANO GALO. Antoniniano. 251253. Antioquía.

A. IMP CC VIB TREB GALLVS AVG. Cabeza radiada a derecha.

R. ADVENTVS AVG. Exergo: VII. emperador triunfante a caballo sosteniendo lanza y cetro.

$3 / 23,1 / 7$.

41.-TREBONIANO GALO. Sestercio. 252. Roma.

A. IMP CAES C VIBIVS TREBONIANVS GALLVS AVG. Busto a derecha.

$R$. APOLL SALVTARI SC. Apolo en pie sosteniendo una palma en su mano derecha, y apoyado sobre una lira encima de una roca. $22,5 / 31 / 1$.

RIC, 103.

42.-TREBONIANO GALO. Sestercio. 253. Roma.

A. Semejante.

R. PM TR P IIII COS II PP SC. Treboniano velado, togado, sosteniendo una pátera sobre un altar y con un cetro corto.

$17,7 / 32,4 / 7$.

RIC, 100.

43.-TREBONIANO GALO. Sestercio. 253. Roma.

A. IMP CAES C VIBIVS TREBONIANVS GALLVS AVG. Busto a derecha.

R. ROMAE AETERNAE. Exergo: SC. Roma sentada sobre trono sosteniendo Victoria y lanza.

$12,8 / 30,2 / 11$.

RIC, 120 .
44.-TREBONiANO GALO. Sestercio. 252. Roma.

A. IMP CAES C VIBIVS TREBONIANVS GALLVS AVG. Busto a derecha.

$R$. APOLL SALVTARI SC. Apolo en pie sosteniendo una palma en su mano derecha y apoyado sobre una lira encima de una roca.

$11,4 / 30 / 12$.

RIC, 103.

45.-EMILIANO. Sestercio. 253. Roma.

A. IMP CAES AEMILIANVS P F AVG. Busto a derecha.

R. APOL CONSERVAT SC. Apolo en pie sosteniendo una lira en su mano derecha y apoyado en una lira encima de una roca.

$18,4 / 27,4 / 11$.

RIC, 43.

46.-VALERIANO I. Antoniniano. 253-254. Roma.

A. IMP C P LIC VALERIANVS AVG. Cabeza radiada a derecha.

$R$. APOLINI PROPVG. Apolo en pie con arco.

$2,9 / 21,6 / 1$.

RIC, 74.

47.-VALERIANO I. Sestercio. 256-257. Roma. A. IMP. C P LIC VALERIANVS P F AVG. Busto a derecha.

$R$. RESTITVTOR ORBIS SC. Valeriano en atuendo militar con una lanza en la mano dando la mano a una mujer arrodillada.

$16 / 27 / 5$.

RIC, 171.

48.-GALIENO. Sestercio. 253. Roma.

A. IMP C P LIC GALLIENVS AVG. Busto a derecha.

R. PAX AVGG SC. Pax en pie sosteniendo cetro atravesado y con el brazo derecho alargado sosteniendo una palma.

15,7/30,2/6.

RIC, 231.

49. - SALONINA. Antoniniano. 258-259. Asia. A. SALONINA AVG. Busto de Salonina diademada y a la derecha.

$R$. IVNO REGINA. Juno en pie manteniendo una pátera y un cetro.

$3,3 / 23,9 / 11$.

RIC, 64 . 


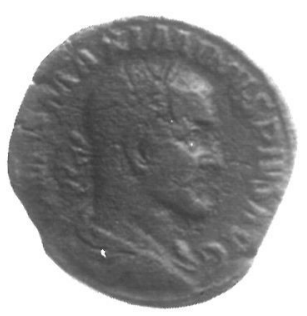

21
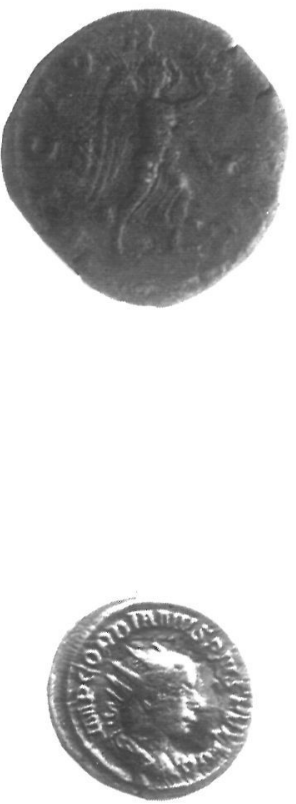

25

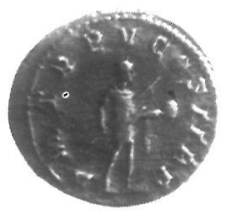

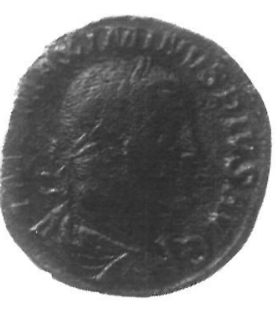

22
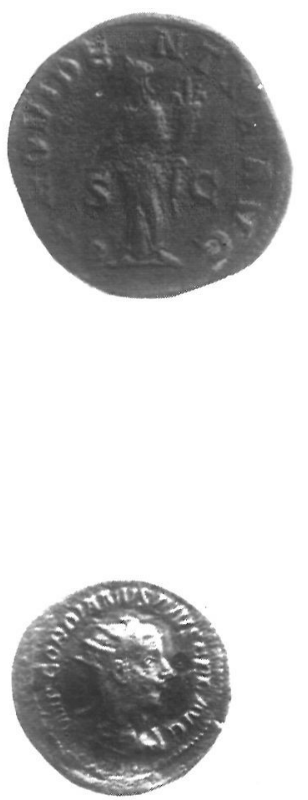

26
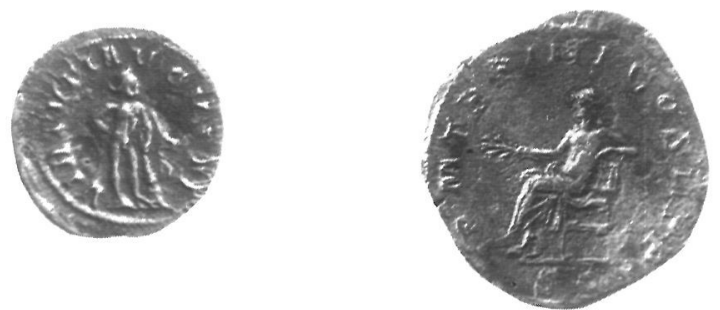

23
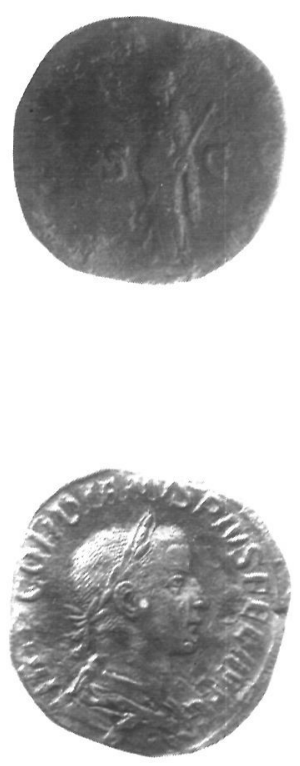

27
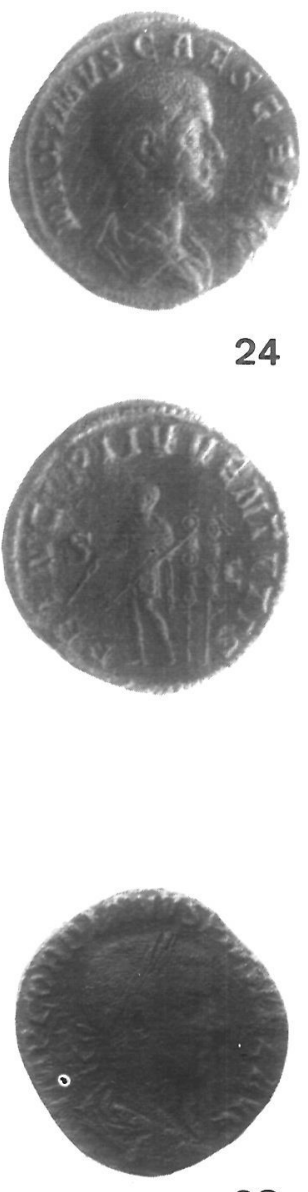

28
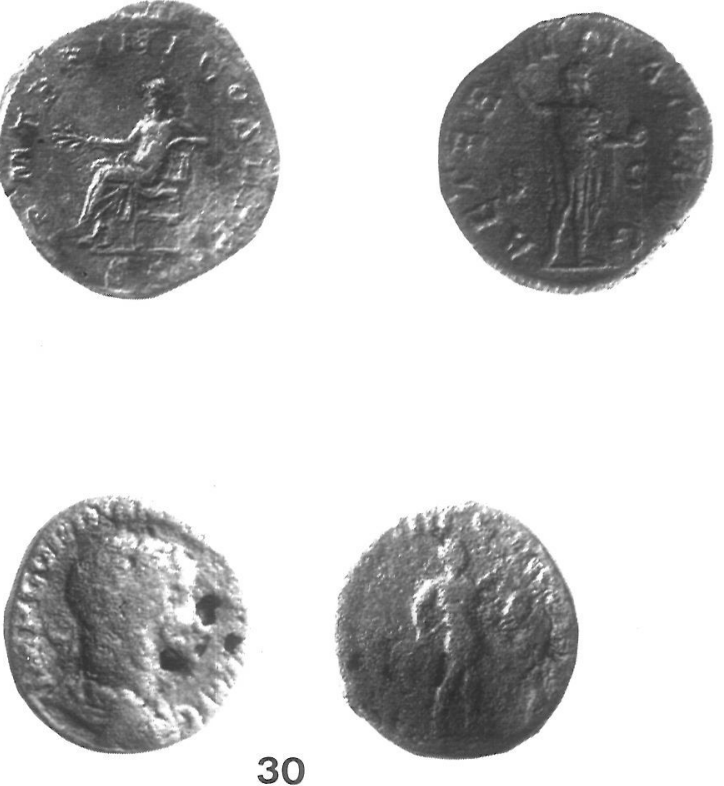

30

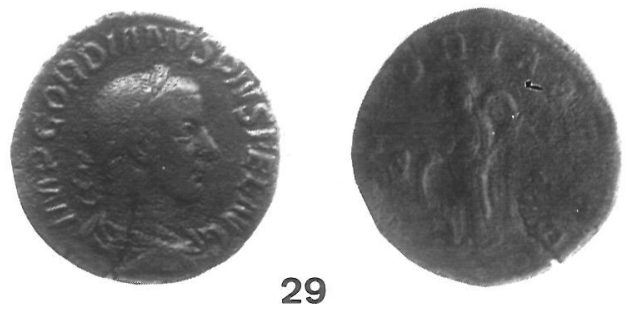

29

Lám. III.-Monedas de Maximino I (n. ${ }^{\circ}$ 21-23), Máximo (n. ${ }^{\circ}$ 24) y Gordiano III (n. $\left.{ }^{\circ} 25-30\right)$. E.-1:1. 
50.- Sestercio.

A. Leyenda borrada. Busto a la derecha.

$R$. LIBERTAS AVG. SC. Libertas en pie.

22/32,3/10.

51.- Sestercio.

A. Leyenda borrada. Emperador a derecha.

$R$. Frustra.

$20,8 / 31,9 / 7$.

52.- - Sestercio.

A. Leyenda borrada. Busto a la derecha.

$R$. Frustra.

20/32,9/--.

53.- Sestercio.

A. Leyenda borrada. Busto a derecha.

$R$. SC (resto leyenda borrada). Victoria marchando a la izquierda.

$20,5 / 30,7 / 11$.

54.- Sestercio.

A. Leyenda borrada. Cabeza masculina a derecha.

$R$. Leyenda borrada. Figura masculina en pie. $23,9 / 33,4 / 11$.

55.- Sestercio.

A. -- L MA --. Cabeza femenina a derecha.

$R$. Leyenda borrada. SC. ¿Júpiter? en pie.

$20,8 / 31,5 / 12$.

56.- Sestercio.

A. Leyenda borrada. Cabeza femenina a derecha.

$R$. Leyenda borrada. Figura en pie. $16,8 / 30,8 / 12$.

57.- Sestercio.

A. Leyenda borrada. Busto laureada a derecha.

$R$. Leyenda borrada. Figura femenina en pie con una cornucopia en la mano izquierda. $23,6 / 31,4 / 6$.

58. - Sestercio.

A. Leyenda borrada. Cabeza femenina a derecha.

$R$. Leyenda borrada. Figura femenina sedente.

$29,1 / 31,3 / 1$.

59. - Sestercio.

A. Leyenda borrada. Cabeza femenina a derecha.

$R$. Leyenda borrada. Figura en pie.

$22,7 / 29 / 10$.
60.- - Sestercio.

$A$. Leyenda borrada. Busto a la derecha.

$R$. Frustra.

$21 / 34,3 /--$

61.-Sestercio.

Frustra en ambas caras.

20,7/33,2/--.

62.-Sestercio.

$A$. Leyenda borrada. Emperador a derecha.

$R$. Frustra.

$21,7 / 32,2 /--$.

\section{Valoración histórica}

Ante todo, la posición geográfica del yacimiento debe ser tenida en cuenta a la hora de plantear su significado histórico. Crevillente y su actual término municipal debían pertenecer en época romana al territorium de Ilici, que constituiría la cabeza jurídica del Bajo Vinalopó y especialmente de la zona interior de este área excesivamente alejada de Lvcentvm, el segundo municipio con rango jurídico en la región.

De nuevo conviene subrayar el doble carácter del hallazgo. Por un lado, el carácter posiblemente estratigráfico de las piezas más antiguas $\mathrm{y}$, por otro, el significado de ocultación del segundo lote que, por su cronología, plantea de nuevo la problemática de las repetidamente cuestionadas invasiones germánicas en la región a mediados del siglo III.

El aprovisionamiento medio del período 222-259 es de 0,94 monedas por año, sin que sea posible establecer las variaciones de períodos más cortos tal y como las realiza Ripollés a propósito de la circulación general en las tierras valencianas (RIPOLLÉS, $1980,162)$. En este período se observa la tendencia general del resto de la Península al mayor aprovisionamiento de numerario de bronce ( 28 piezas), frente a una relativa escasez de la plata ( 7 piezas). En este sentido, la exclusiva presencia de sestercios dentro de la producción de bronce prueba una vez más el mantenimiento del sistema monetario altoimperial.

Desde los trabajos de Taracena sobre las invasiones germánicas en la Península en la segunda mitad del siglo III (TARACENA, 1950) son muchos los autores que han puesto en relación los hallazgos monetarios de fechas-límite cercanas al 260 con estos acontecimientos (BALIL, 1957; BLÁZQUEZ, 1964, 1968 y 1973; HIERNARD, 1980; PALOL, 


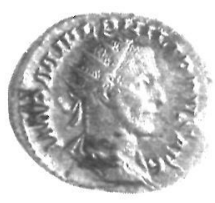

31
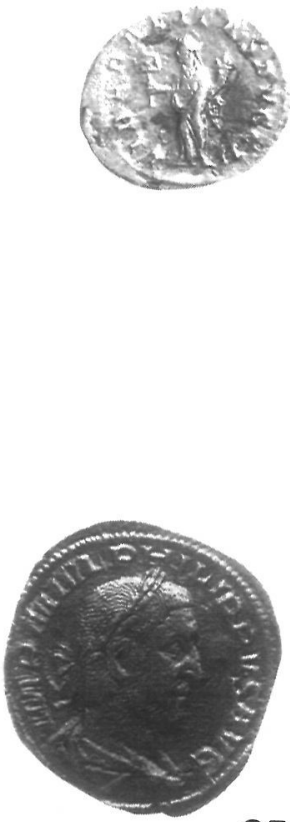

35

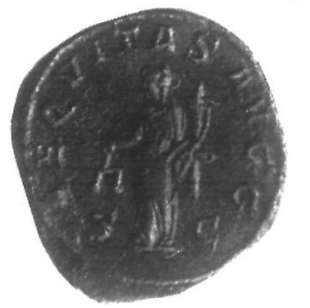

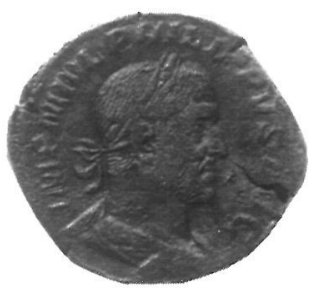

36

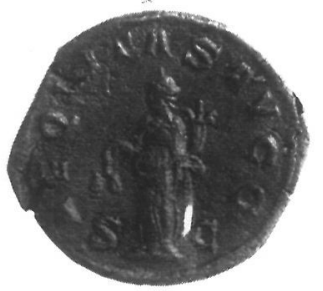

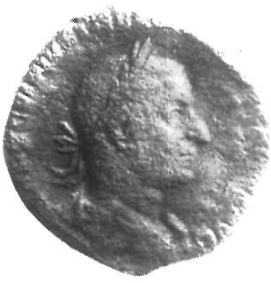

33
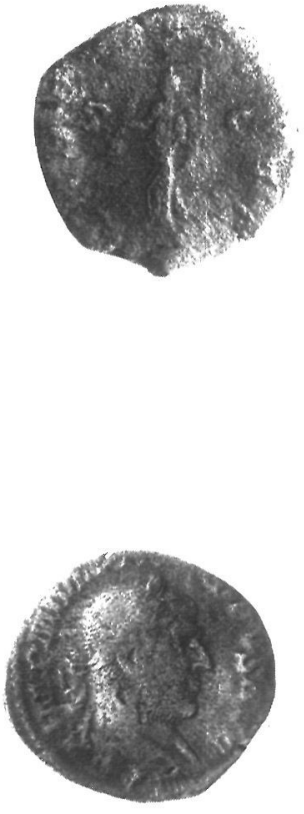

37

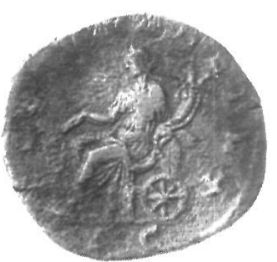

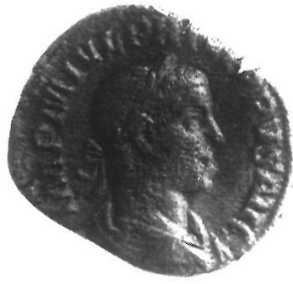

34
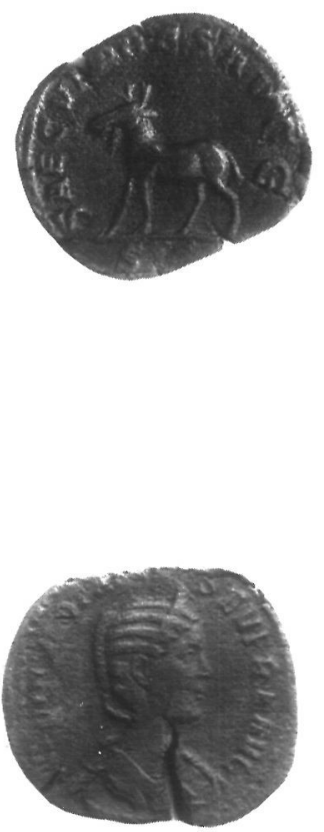

38

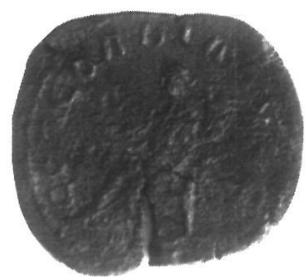

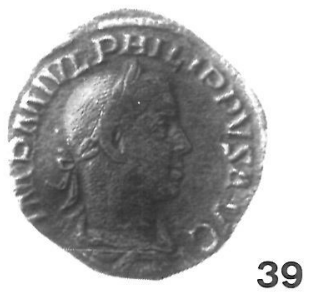
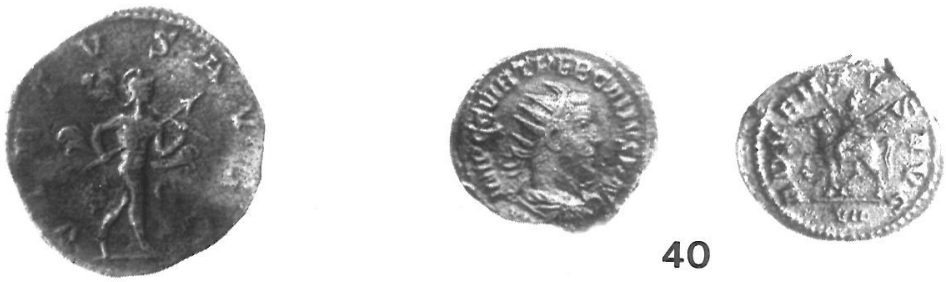

Lám. IV.-Monedas de Filipo I (n. $\left.{ }^{\circ} 31-37\right)$, Otacilia (n. $\left.{ }^{\circ} 38\right)$, Filipo II (n. $\left.{ }^{\circ} 39\right)$ y Treboniano Galo (n. $\left.{ }^{\circ} 40\right)$. E.-1:1. 
1978; RAMOS FOLQUÉS, 1956; RAMOS FERNÁNDEZ, 1975; RIPOLLÉS, 1980 y TARRADELL, 1955, 1957, 1977, entre otros).

A la vista de todos estos datos se hace preciso distinguir entre lo que son simples acumulaciones de numerario en circulación (ocultaciones) y los tesorillos formados en función del valor metálico de las piezas (tesaurizaciones), tal y como han indicado recientemente algunos autores (CAMPO-GURT, 1980, 130).

Resulta evidente que para la consideración de las referidas invasiones sólo deben ser tenidos en cuenta los conjuntos que signifiquen ocultaciones, una de las cuales vendría constituída por las piezas aquí estudiadas.

El freno en el volumen de circulación a partir del año 260 ha sido observado con claridad en los hallazgos de la costa catalana y Baleares (CAMPOGURT, 1980, 136), en contraste con los datos obtenidos en otros puntos de la Península. En este sentido, Conimbriga presenta a partir del año 260 un notable incremento en el aporte de numerario (PEREIRA et alii, 1974, 234), situación paralela a la de Clunia (GURT, 1985, 155) y, en menor medida, Tarraco, que se aparta de las precedentes por la menor intensidad de los aportes monetales bajo Galieno (HIERNARD, 1980).

Los hallazgos de Tarragona y las ocultaciones conocidas hasta la fecha muestran una notable recesión en los aportes monetarios en la franja mediterránea a partir del 260 . Este dato debe ponerse en relación con las fechas de algunas de estas ocultaciones, que se constituirían en datos post quem para fijar las invasiones germánicas en el área. Los conjuntos aducidos en repetidas ocasiones con este objeto han sido principalmente el de Castellón (MATEU Y LLOPIS, 1952), con una cronología límite del 260, y el de Altafulla, Tarragona (MATEU Y LLOPIS, 1950 y 1951 principalmente), fechas que indujeron a Balil a situar el «raid» germánico en el 262 (BALIL, 1957, 139). Incluso cabría añadir otro conjunto tarraconense (HERNÁNDEZ SANAHUJA et alii, 1894, 320-323), cuya cronología límite se sitúa con Galieno-Salonina (véase mapa de distribución de tesoros y ocultaciones del período en PEREIRA et alii, 1974, 232).

Con todos estos antecedentes, el hallazgo de Crevillente cobra una especial significación al proporcionar nuevamente una cronología que se ajusta a las tesis planteadas hasta la fecha, ya que por su ubicación puede ser un nuevo eslabón cara al fenómeno de los violentos fenómenos del siglo III, considerando el carácter acumulativo del numerario en circulación al que hemos aludido.

\section{BIBLIOGRAFİA}

BALIL, A. 1957, «Las invasiones germánicas en Hispania durante la segunda mitad del siglo III d. C.», en Cuadernos de Trabajos de la Escuela Española de Historia y Arqueología en Roma IX, 97-143.

BLÁZQUEZ, J. M. ${ }^{\text {a }}$ 1964, Estructura económica y social de Hispania durante la anarquía militar y el Bajo Imperio. Cuadernos de la Cátedra de Historia Antigua de España. Madrid.

- 1968, «La crisis del siglo III en Hispania y Mauritania Tingitana», en Hispania XXVIII, 23-34.

- 1973, «El Imperio y las invasiones desde la crisis del siglo III al año 500», en Historia económica y social de España I, La Antigüedad, Madrid, 329-450.

CAMPO, M. Y GURT, J. M. ${ }^{\mathrm{a}} 1980$, «El problema en la crisis del siglo III: su reflejo en los hallazgos monetarios realizados en la costa catalana y Baleares", Numisma 165-167, 129-140.

GURT, J. M. ${ }^{a} 1985$, Clunia III: hallazgos monetarios. EAE 145. Madrid.

HERNÁNDEZ SANAHUJA, B, y DEL ARCO Y MOLINERO, D. A. 1894, Catálogo del Museo Arqueológico de Tarragona. Tarragona.

HIERNARD 1980, «Tarragone: la circulación monétaire au IIIème siècle ap. J. C.», en I Symposium numismático de Barcelona I, Barcelona, 83-89.

MATEU Y LLOPIS, F. 1950, «El hallazgo de denarios romanos de Altafulla», en Boletín Arqueológico XXX, 53-58.

- 1951, «Hallazgos monetarios VI», Ampurias XIII, 203-255.

- 1952, «Hallazgos monetarios VII», Num. Hispan. I, 1-2, 225-264.

PALOL, P. de 1978, El Baix Imperi. Historia de Catalunya I, Barcelona, 239-256.

PEREIRA, I; BOST, J. P. y HIERNARD, H. 1974, Fouilles de Conimbriga III, Les monnaies. París.

RAMOS FERNÁNDEZ, R. 1975, La ciudad romana de Ilici, estudio arqueológico. Alicante.

RAMOS FOLQUÉS, A. 1956, «Las invasiones germánicas en La Alcudia (Elche)». I Congreso Español de Estudios Clásicos.

RIPOLLÉS, B. 1980, La circulación monetaria en las tierras valencianas durante la Antigüedad. Barcelona.

TARACENA, B. 1950, «Las invasiones germánicas en España durante la segunda mitad del siglo III d. C.», I Congreso internacional de Pirenaístas. Zaragoza.

TARRADELL, M. 1955, «Sobre las invasiones germánicas del siglo III d. C. en la Península Ibérica», Estudios Clásicos III, n. ${ }^{\circ} 15,95-110$.

- 1957, «Problemas cronológicos de las invasiones germánicas del siglo III (d. C.)», IV CNA (Burgos), Zaragoza, 231-239.

- 1977, «Primeras notícies de la crisi del segle III. d. C. a Mallorca», Memoria de l'Institut d'Arqueología i Prehistòria, Univ. de Barcelona, 27-32. 


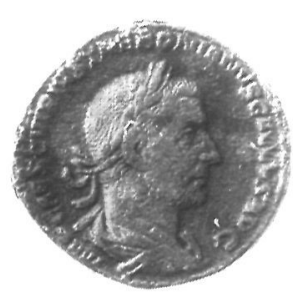

41
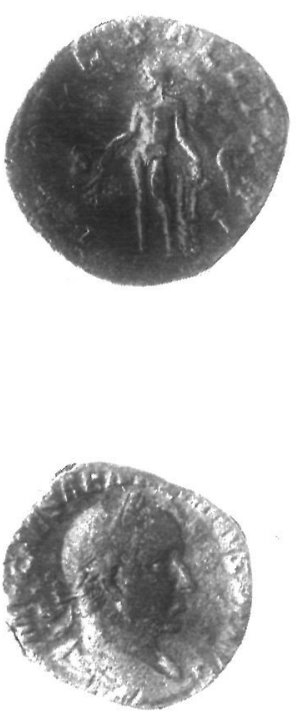

45
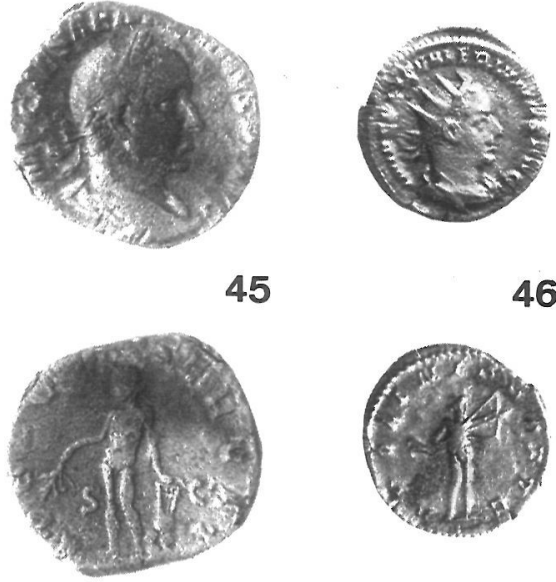

46

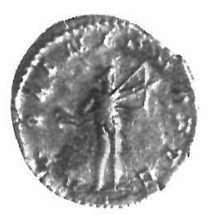

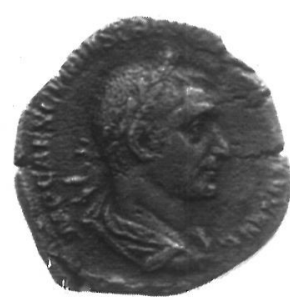

43
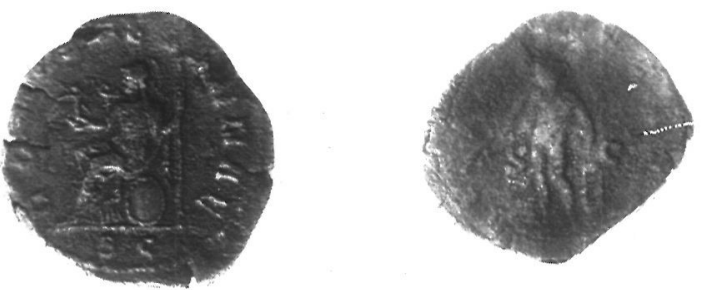
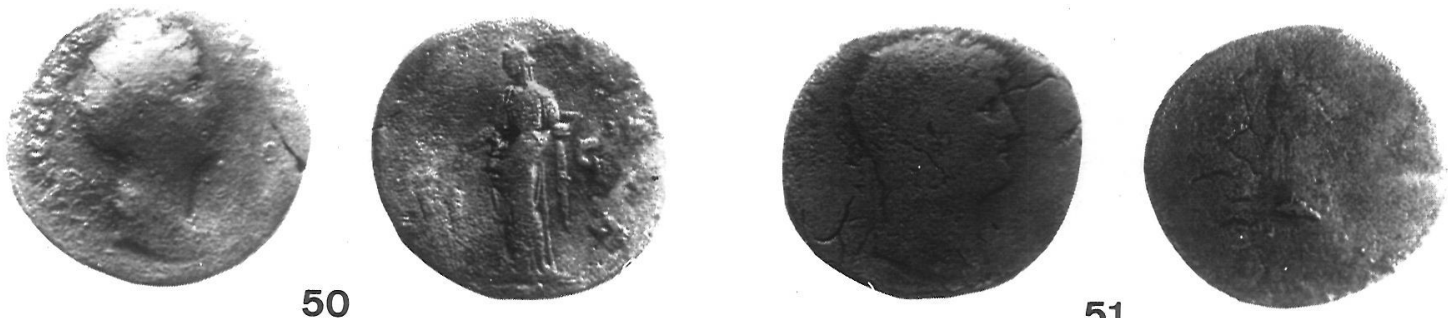

Lám. V.-Monedas de Treboniano Galo (n. $\left.{ }^{\circ} 41-44\right)$, Emiliano (n. $\left.{ }^{\circ} 45\right)$, Valeriano I (n. $\left.{ }^{\circ} 46-47\right)$, Galieno (n. $\left.{ }^{\circ} 48\right)$, Salonina (n. ${ }^{\circ} 49$ ) y dos ejemplares no clasificados (n. ${ }^{\circ}$ 50-51). E. - 1:1. 


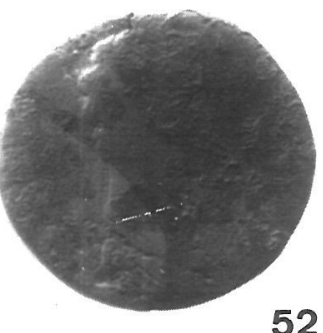

52

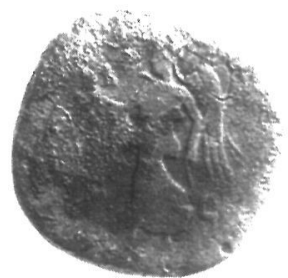

53

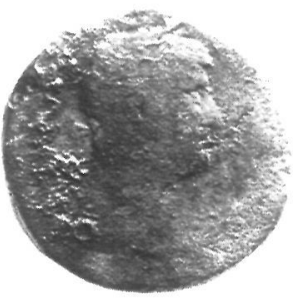

57
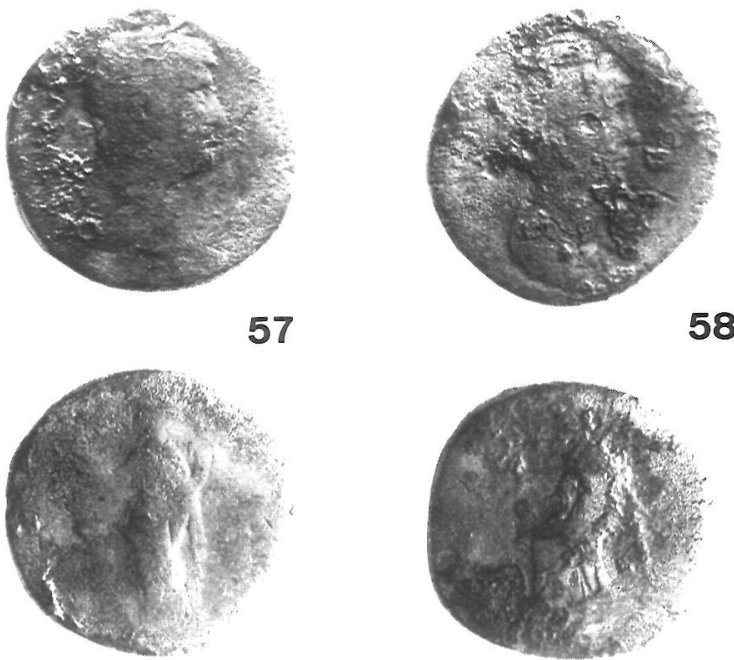

58

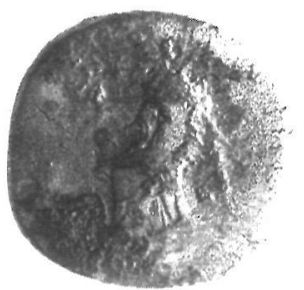

54
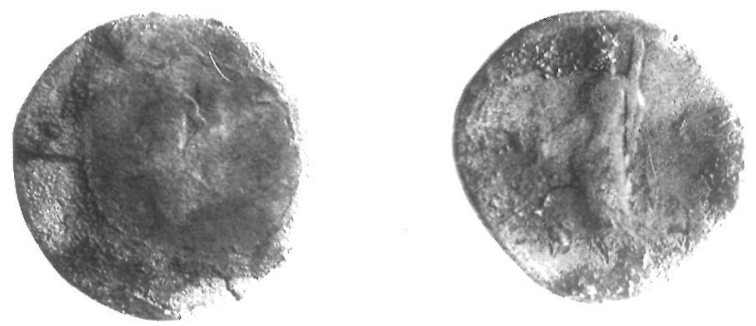

55

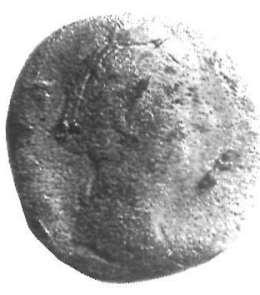

59
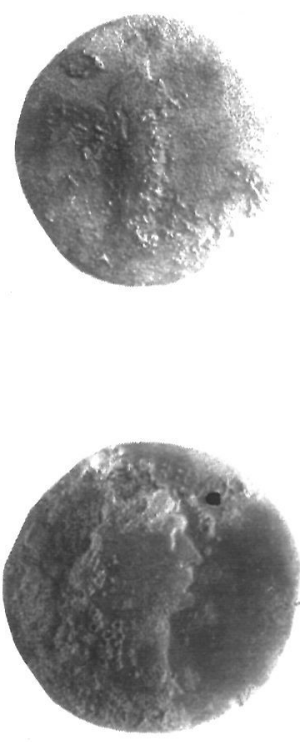

62
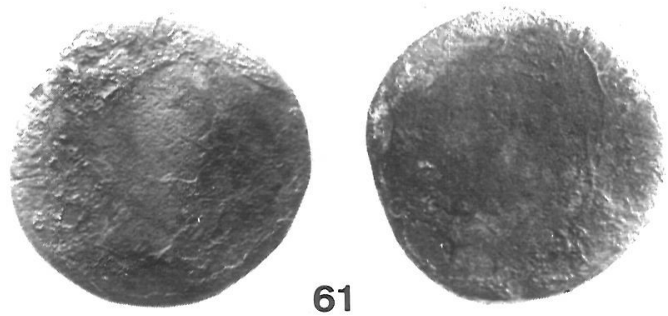

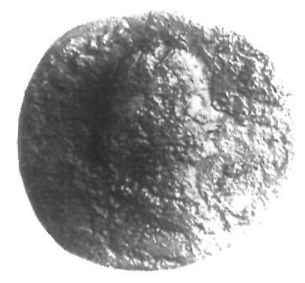

56

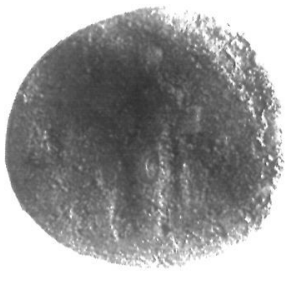

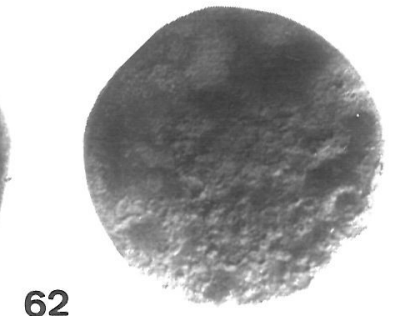

Lám. VI.-Monedas no clasificadas por causa de su estado de conservación (n. ${ }^{\circ}$ 52-62). E. -1:1. 